\title{
ANALYSIS OF THE CORRELATION BETWEEN FRACTAL DIMENSION OF GRAVELLY SOIL AND DEBRIS-FLOW INITIATION THROUGH IN-SITU EXPERIMENTS
}

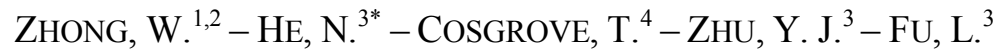 \\ ${ }^{1}$ Institute of Mountain Hazards and Environment, Chinese Academy of Sciences, \\ Chengdu 610041, China \\ ${ }^{2}$ Key Laboratory of Mountain Hazards and Surface Processes, Chinese Academy of Sciences, \\ Chengdu 610041, China \\ ${ }^{3}$ School of Civil Engineering, Henan Polytechnic University, Jiaozuo, Henan 454003, China \\ ${ }^{4}$ Department of Civil Engineering \& Materials Science, University of Limerick, \\ Limerick, Ireland \\ *Corresponding author \\ e-mail:hn61886@163.com; phone:+86-133-2382-2010
}

(Received 27 $7^{\text {th }}$ Feb 2019; accepted $3^{\text {rd }}$ May 2019)

\begin{abstract}
Particle size distribution of the gravelly soil in debris flow source area has a great impact on the formation mechanism of debris-flow. In order to explore the relationship between particle composition and debris flow initiation, we collected 182 soil samples from debris flow source areas. Sieving tests have been conducted in the laboratory to acquire the fundamental particle size distribution data. Subsequently, the fractal theory was employed to compute the fractal dimension of each soil sample, analyzing the results of calculation we found that the gravelly soil in debris flow source area is mainly concentrated in one fractal dimension, the value of which ranges from about 2.250 to 2.798. Comparing the results of calculation and sieving experimentation, the underlying relationship between particle composition and fractal dimension can be revealed: the particle compositions of the gravelly soil tend to remain uniform as the fractal dimension increases. On the basis of the calculation results, the in-situ artificial rainfall experiments can be designed and performed. Analyzing the phenomenon during the processes of the experiments, the initiation mechanism with different fractal dimensions can be preliminarily identified: The gravelly soil which can mobilise into debris flows exhibits significant criticality feature, and the gravelly soil with fractal dimension ranges from 2.4 to 2.6 are more susceptible to mobilise into debris flow, and the scale of the debris flow is relatively larger. For slopes with fractal dimension $<2.4$, the possibility of mobilisation into debris flow is extremely low. When fractal dimension ranges from about 2.6 to 2.7 , the density of the formed debris flow is relatively lower, under which the formation of debris flows exhibits significant intermittent characteristics.
\end{abstract}

Keywords: debris flow, fractal theory, particle size distribution, initiation mechanism, in-situ experiments, disaster mitigation

\section{Introduction}

Debris flows form a class of slope failures (Varnes, 1978) encompassing a wide range of characteristics and varying widely in magnitude (Jakob, 2005), composition (Coussot and Meunier, 1996), and mechanism of initiation (Coe et al., 2008a). Debris flows are recognized as a significant hazard in mountainous areas, and have been shown to be an important process controlling the transport of sediment and woody debris from hill slopes to channels in mountainous areas, with implications for channel form and riparian habitat (Brayshaw, 2009; Hogan and Schwab, 1991; Smadja, 1992). Because of 
their high mobility, velocity and density, debris flows can be very destructive and damaging when they encounter infrastructure such as buildings, roads, bridges, pipelines and hydropower facilities, and may lead to loss of human life (Park et al., 2016; Chen and Lee, 2000; Gregoretti et al., 2016; Wang et al., 2017).

To mitigate and prevent hazards induced by debris flows and related risks, one must understand the formation of these in order to make reliable forecasts ( $\mathrm{Yu}$ et al., 2014). Many factors are related to the occurrence of debris flows such as the basin gradient, the percentage of basin area with slopes greater than or equal to $30 \%$, basin ruggedness, slope aspect, rainfall intensity, and soil properties, including the clay percentage, the percentage of organic matter, the soil composition, and the soil liquid limit (Cannon et al., 2010; Liu et al., 2009). Many researchers have focused on the prediction of their occurrence (Bathurst et al., 1997; Giannecchini et al., 2007; Ho et al., 2000) and estimation of their magnitude and runout distance (Hungr et al., 2008; Johnson et al., 2000; Miller and Burnett, 2008) in order to reduce associated risk. In addition, established prediction models include the Water-Soil coupling forecast model, the I-D (rainfall intensity-duration) prediction model and other statistical prediction models (Yang et al., 2016, 2002; Saito et al., 2010; Zhang et al., 2014a, b). Moreover, other parameter combination modes for defining a threshold for debris flow activity in terms of mean intensity, duration and mean annual precipitation were also presented for the debris flow prediction of dolomites in northeastern Italy (Bacchini and Zannoni, 2003; Giannecchini et al., 2016; Maggioni et al., 2016; Papa et al., 2013). Some researchers carried out experiments on slope stability considering mechanical property variations of the soil mass and established the model of debris flow initiation (Berti and Simoni, 2005; Iverson and LaHusen, 1989; Iverson et al., 1997). Other scientists used different approaches and discussed the relationship between particle composition and properties of debris flows (Li et al., 2007; Yong et al., 2013, 2005), and some models have been established (He et al., 2014; Ningsheng et al., 2004; Zhou et al., 2012), which greatly facilitate debris flows prediction and mitigation. However, due to the complexity of debris flow formation and subsequent dynamic process, the accuracy of the prediction often cannot meet adequately the requirements of disaster mitigation (Turkington et al., 2016). Prediction models based on the formation mechanism of debris flows promises an effective way to ameliorate the impact of such disasters.

Basically, three necessary conditions are required to fulfill debris flow initiation: energy conditions (slope gradient), meteorological conditions (rainfall condition) and material condition (particle size distribution and density). In the short term, the energy conditions can be taken as a constant, and the precipitation can be measured at nearby meteorological stations. The mechanical property of the loose solid material plays an extremely important role in debris flow initiation. From soil mechanics we know that the soil mechanical property with the major influence on debris flow initiation is soil composition. Therefore, identifying the particle size distribution of the loose solid material is the precondition for an accurate analysis of debris flow initiation. But the particle size distribution of the gravelly soil in the debris-flow source area is so wide that the critical particle grading features are not yet well understood. The composition and gradation of the particles in debris flow source areas have significant influence on debris flow formation, subsequent movement and resulting dynamic forces (Chen et al., 2010; He et al., 2016). Previous studies explored the characteristics of the gravelly soil (Li et al., 2007; MacDonald et al., 2012), and some models were established to reveal the relationship between mechanical properties of the gravelly soil and its particle size 
distribution (Chen, 2004; Hwang and Powers, 2003; Shimizu et al., 2011; Wang and Sassa, 2003; Zhou et al., 2012), but the influential of particle composition on debris flow initiation is still unclear. In addition, the complexity of the particle size distribution results in a non-deterministic and anisotropic gravelly soil structure, which poses great difficulties when attempting to use traditional methods based on linear analysis to quantitatively describe

it (https://www.benthamopen.com/contents/pdf/TOCIEJ/TOCIEJ-10-877.pdf).

Based on the aforementioned discussion, to better understand the characteristics of the gravelly soil and reveal the relationship between mechanical properties and debris flow initiation, the main objective of this paper is to explore the characteristics of particle size distribution taken from areas prone to debris flows, and using fractal theory to calculate the fractal dimension of each sample. After the particle size distribution is established, the fractal dimension can be calculated, and the fractal characteristics can be fully understood. Taking into account of this data, the in-situ artificial rainfall experiments can then be conducted. By analyzing rainfall data, water content, and pore water pressure, the initiation mechanism of debris flow can be revealed, and the influence of particle composition on debris flow initiation can be identified, which in turn can greatly facilitate future debris flow prediction and mitigation.

\section{Methodology}

In this research, 182 soil samples were taken from 116 gullies before September 2013 that were identified highly prone to debris flows (all of the gullies are situated on Longmenshan fault zone; Fig. 1). The soil samples were sorted and dried in the laboratory to facilitate the sieve tests. Using sieve tests, the particle size distribution curves were established, and plotted in both plane-coordinate and double logarithmic coordinates.

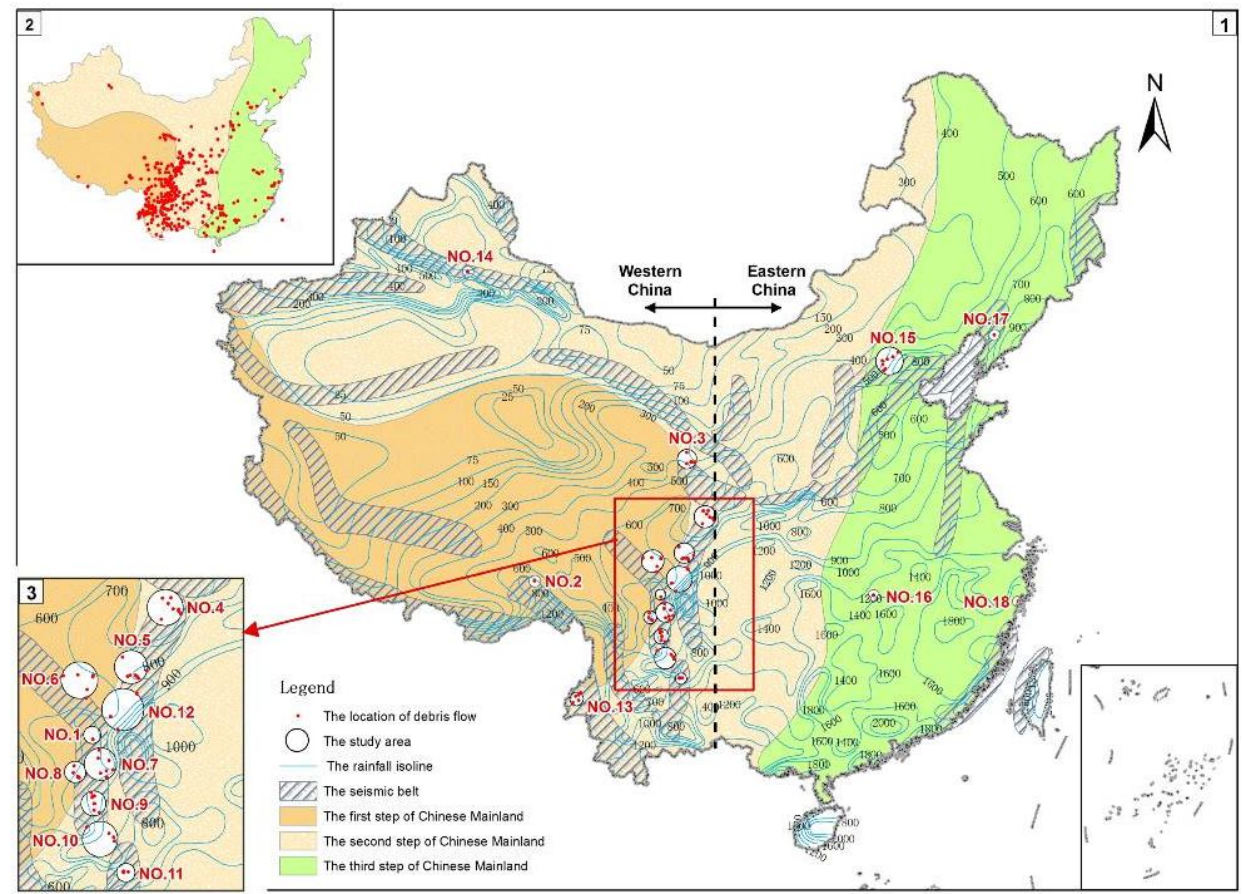

Figure 1. Sampling sites (Lu, 2013) 


\section{Fractal theory}

The gravelly soil in the debris-flow source areas shares some characteristics with the fragmented rocks. Therefore, the particle fractal dimension can be calculated using a rock-crushing model, which is derived from fractal theory (Carpinteri et al., 2004; Chen Yong, 1998). It is presumed that the diameter of a gravelly soil particle is $R$, while $N(R)$ denotes the number of particles whose diameter is larger than $R$, and these two parameters satisfy the general fractal equation:

$$
N(R)=R^{-D}
$$

where D is the fractal dimension. After differentiating we obtain Equation 2:

$$
d N(R) \sim R^{-D-1} d R
$$

The particle size distribution and frequency of gravelly soil fits the Weibull distribution well:

$$
\frac{M(<R)}{M_{0}}=1-\exp \left[-\left(\frac{R}{R_{0}}\right)^{k}\right]
$$

where $M(<R)$ denotes the total mass of the particles whose diameter is smaller than $R$, $M_{0}$ is the total mass of the gravelly soil, $R_{0}$ is the average diameter of the gravelly soil, and $k$ is a constant. For $R<<R_{0}$, Equation 3 was further manipulated, ignoring the quadratic term, and the following equation is obtained:

$$
\frac{M(<R)}{M_{0}}=\left(\frac{R}{R_{0}}\right)^{k}
$$

From which we obtain Equation 5:

$$
d M(<R) \sim \mathrm{R}^{\mathrm{k}-1} d R
$$

The particle number of the gravelly soil and the mass of the gravelly soil satisfies the following equation:

$$
d M(<R) \sim \mathrm{R}^{3} d N(R)
$$

Combining Equations 2, 5 and 6, the following equation can be derived:

$$
\mathrm{D}=3-\mathrm{k}
$$

Equation 7 is the function employed in this paper to calculate the fractal dimension, where $\mathrm{D}$ is the fractal dimension, while $\mathrm{k}$ is the slope of the line we are fitting in the 
double logarithmic coordinates, where the $\mathrm{X}$-axis is $\lg R$ and the $\mathrm{Y}$-axis is $\lg \left[M(<R) / M_{0}\right]$.

A fractal phenomenon approximates self-similarity or statistical self-similarity. This similarity exists only within a certain range of scales. Therefore the similarity will not exist outside certain ranges. Outside of these ranges the objects do not possess fractal feature, which indicates the fractal scale-free interval is limited. On the basis of the complexity and particular nature of the gravelly soil, this paper chooses the coefficient of determination $\left(R^{2}\right)$ of the fitted line as the index to determine if the soil samples possesses fractal features or not. If the coefficient of determination $\left(R^{2}\right)$ of the fitted line is greater than 0.9 , it means that the soil samples present good similarity and the fractal dimension can be calculated through $D=3-k$. On the other hand, if the coefficient of determination $\left(R^{2}\right)$ of the fitted line is less than 0.9 , the soil samples do not have fractal features, and Equation 7 cannot be employed to calculate the fractal dimension.

\section{Fractal features of the gravelly soil in debris flow source area}

In total, 182 samples were sorted and prepared first (Fig. 2). Using sieve tests, the particle size distribution data were acquired and the particle size distribution curves were plotted using plane-coordinates and a double logarithmic scale (Figs. 3 and 4). By means of linear fitting we obtained the slope of the straight line, and then Equation 7 was employed to calculate the fractal dimensions of all 182 soil samples. On analyzing the results, we found that the soil samples were mainly concentrated in one fractal dimension. About 161 soil samples satisfied the requirements of fractal theory well, and one fractal dimension accounted for $88.46 \%$ of the total samples. Therefore, we concluded that the gravelly soil is mainly concentrated in one fractal dimension. The dimension value ranges from about 2.25 to 2.98. The sample with the largest dimension was taken from Jiangjia gully, while the smallest was taken from Ganxi gully, and their double logarithm curves are depicted in Figure $4 a$ and $b$, respectively. The distribution interval of one fractal dimension is illustrated in Figure 5. Through Figure 5, we found that the fractal dimensions of the 130 soil samples are within the range of 2.4-2.7, with one fractal dimension accounting for $80.75 \%$ of the total samples. This raises an obvious question: is it the case that gravelly soil with fractal dimension ranging from 2.4 to 2.7 is more susceptible to debris flow? This question merits further study in the future.
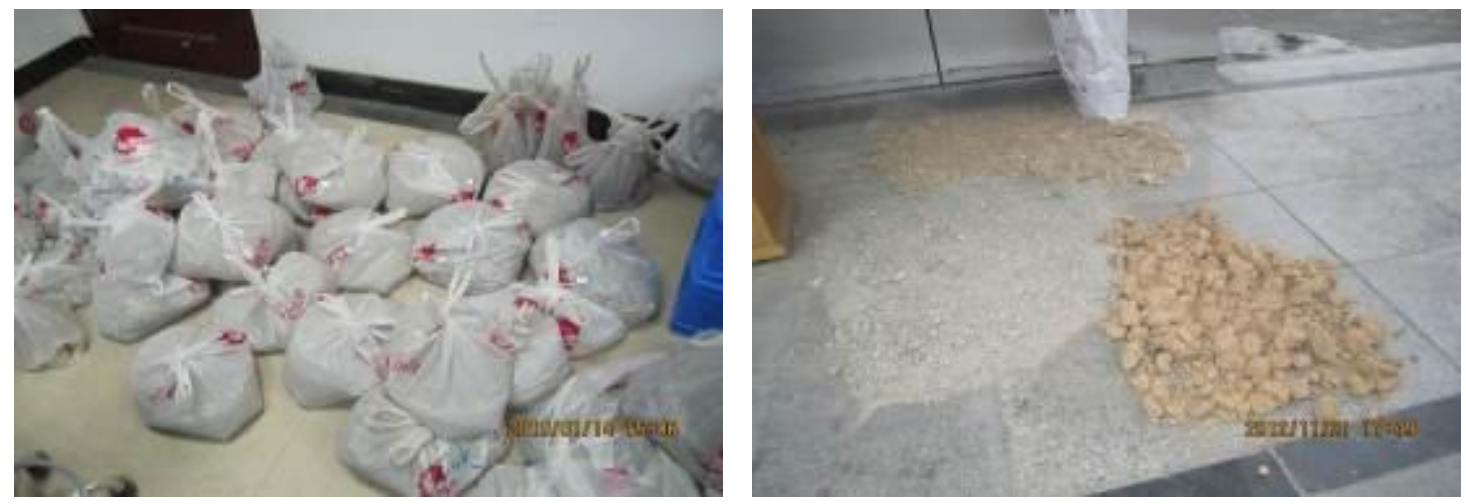

Figure 2. Sorting and drying the soil in the laboratory 


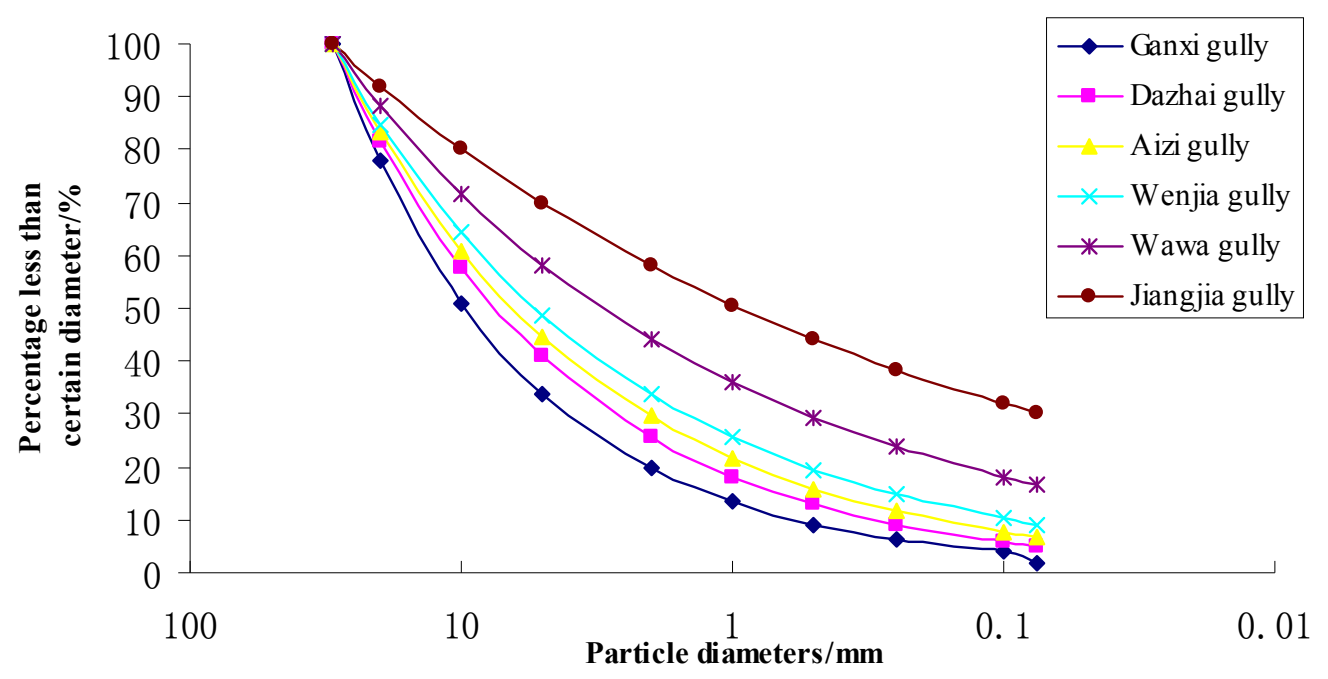

Figure 3. Particle size distribution curves

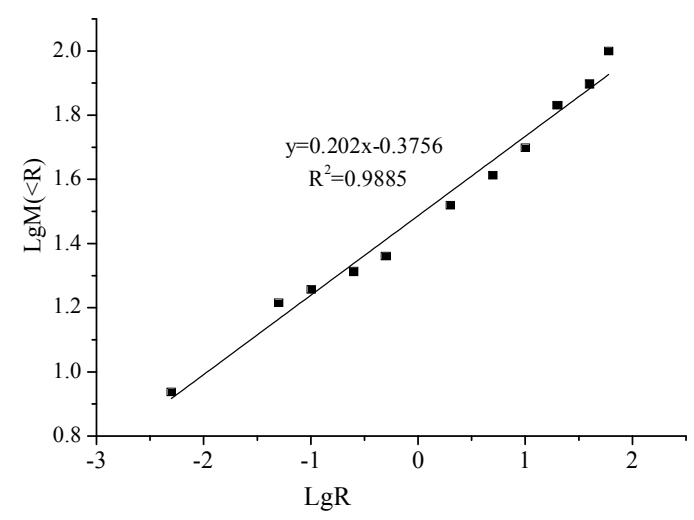

a. Sample from Jiangjia gully

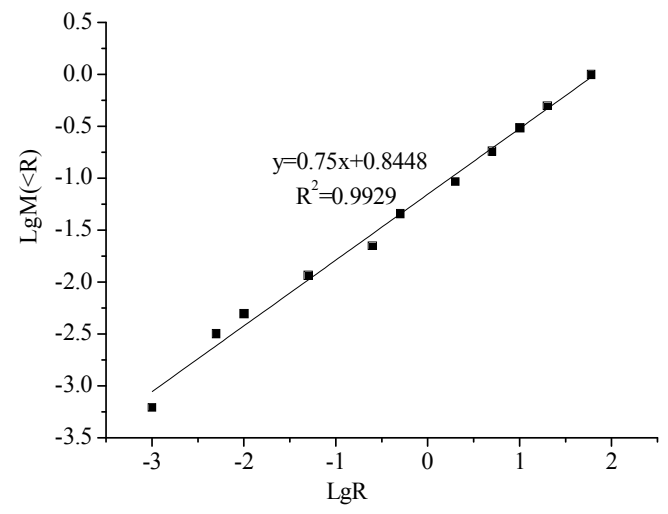

b. Sample from Ganxi gully

Figure 4. Double logarithm curves of Jiangjia gully and Ganxi gully (where R denotes the diameter of the particles, while $M(<R)$ is the percentage whose diameters are less than $R$ )

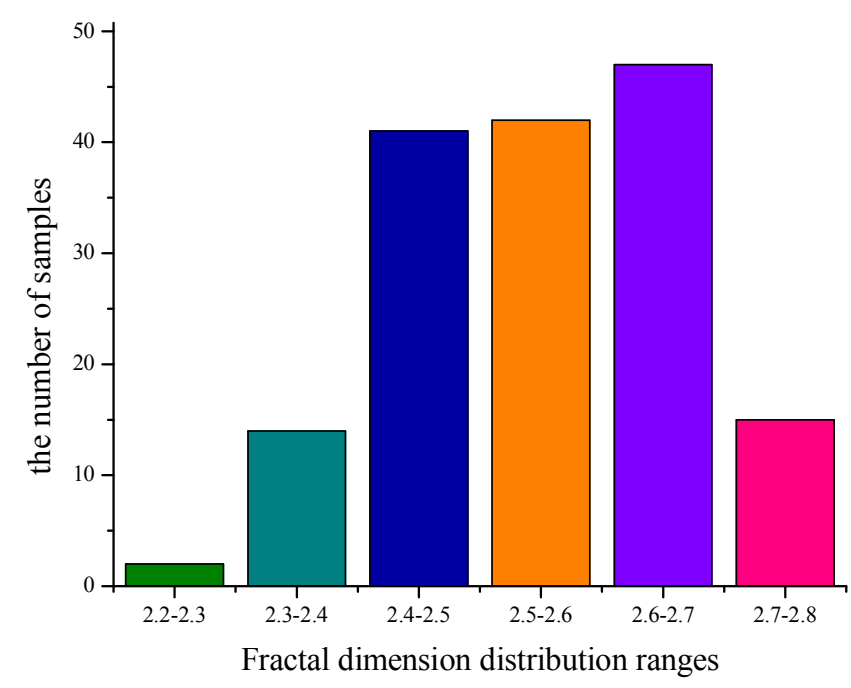

Figure 5. Distribution interval of one fractal dimension 
By comparing Figures 3 and 4, we found that the particle size distribution tends to remain uniform as the fractal dimension increases. In addition, as the coarse particle content increases, the fractal dimension decreases. The particle composition determines the kind of skeleton or mechanical properties of the gravelly soil, which in turn determines the strength and hydraulic conductivity.

Figures 3 and 4 illustrate that the fractal dimension varied with the particle size distribution. The more uniform the particle size distribution, the larger the fractal dimension becomes. The larger particles formed the skeleton of the gravelly soil, while the relatively smaller particles filled the pores. For soil samples with larger fractal dimension, the pores formed by larger particles are well filled with small particles. Under such circumstances, the hydraulic conductivity can be greatly reduced. Moreover, the strength of a gravelly soil with a larger fractal dimension is mainly provided by cohesion and sliding friction between particles. As the fractal dimension decreases, the porosity formed by larger particles could not be fully filled by the smaller particles. Therefore, the hydraulic conductivity becomes larger. For soil samples with a smaller fractal dimension, the strength of the soil is mainly determined by cohesion and occlusal friction.

In addition, soil strength plays a crucial role in slope stability analysis. Debris-flow initiation can generally be subdivided into two mechanisms: 1) failure of shallow landslides, which transform into debris flows, and 2) concentrated run-off (flash flood) erosion in channels filled with sediments, which may be augmented by landslides from the slope. To better understand the debris-flow initiation mechanism, the relationship between fractal dimension of gravelly soil and debris-flow initiation was investigated by conducting in situ artificial rainfall experiments in areas prone to debris flow.

\section{In-situ debris flow initiation experiment}

Based on the aforementioned dataset, a debris flow initiation experiment can be designed and conducted. A schematic diagram of the experiment is shown in Figure 6. The artificial rainfall experiment involved mainly the following equipments: an artificial rainfall system (water pump, water tank, bracket and spay nozzle), rainfall gauge, pore-water pressure sensors, water content sensors, video camera, and data collection system. As noted in section 2.2 we found that the soil fractal dimension ranges from about 2.25 to 2.98. Therefore we selected 2.3, 2.35, 2.4, 2.45, 2.5, 2.55, 2.6 and 2.7 as the experimental fractal dimension value to back-calculate the corresponding particle compositions. Through field investigation the dry density of the gravelly soil can be determined. The dry density ranges from 1.55 to $2.2 \mathrm{~g} / \mathrm{cm}^{3}$. In this research the dry density of the soil sample was assumed as $1.7,1.8$ and $1.9 \mathrm{~g} / \mathrm{cm}^{3}$, respectively. Previous research revealed that slope angle ranging from 25 to $45^{\circ}$ gives favourable conditions for debris flow initiation. Due to the complexity and difficulties in the process of performing in-situ experiments, the slope angle is assumed as $35^{\circ}$. The slope size is $1.5 \mathrm{~m} \times 2.3 \mathrm{~m}$, the position and depth of the sensors are shown in Figure 6 . A total of 12 sensors were used in the experiment. The sensors are buried in six locations, 0.7 and $0.17 \mathrm{~m}$ in depth, and 0.7 and $1.5 \mathrm{~m}$ away from the upper edge of the experimental slope. Rainfall intensity is $75.2 \mathrm{~mm} / \mathrm{h}$ during the experiments, and the duration time are mainly dependent on the initiation of debris flows, after debris flow initiated, the rainfall processes will last 30-40 minutes in order to identify the scale of the debris flows. 


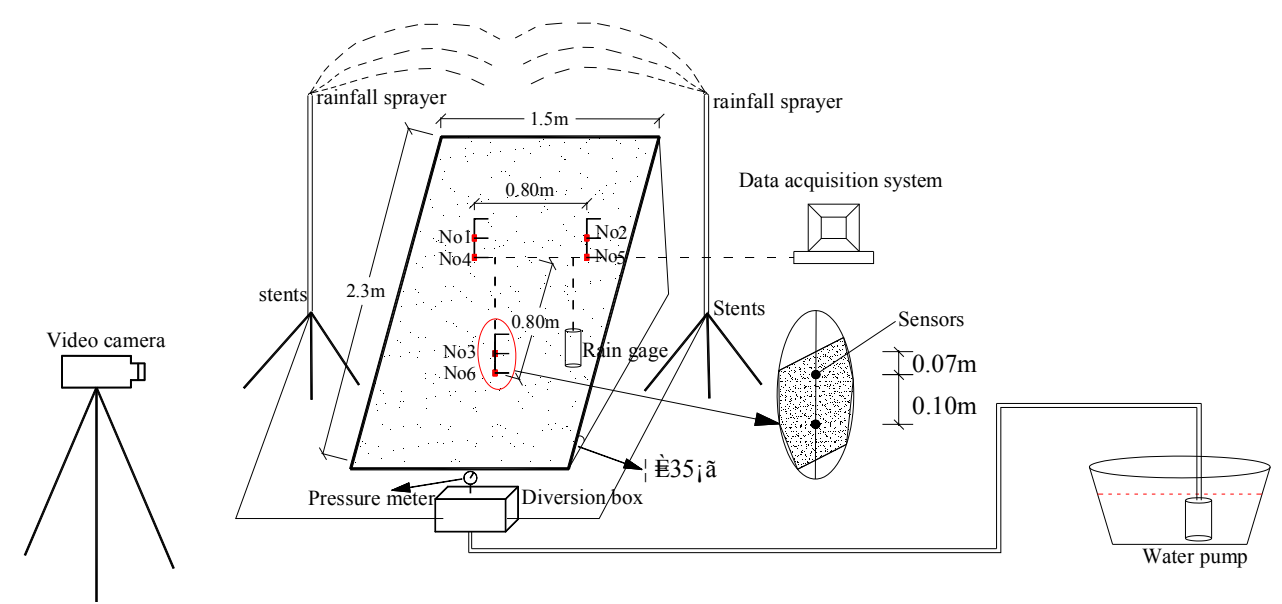

Figure 6. Experimental scheme figure

\section{Test preparations}

Based on the selected fractal dimension value, the particle size distribution for different particle diameters and different dry densities can be back-calculated, and the soil sample can be prepared. Subsequently the prepared soil can be placed on the slope at the chosen slope angle and the sensors positioned as shown in Figure 7. Based on the typical debris flow records in the past, most rainfall intensities that induced debris flows are over $30 \mathrm{~mm} / \mathrm{h}$, and in some areas they can exceed $100 \mathrm{~mm} / \mathrm{h}$. In this study, the rainfall intensities are controlled by a water pump. The sprinkler nozzle is $11 \mathrm{~mm}$ in diameter, and the rainfall intensity is set at $75 \mathrm{~mm} / \mathrm{h}$. The actual rainfall intensity of the experiment is found to be $75.2 \mathrm{~mm} / \mathrm{h}$ during calibration. Then the rainfall gauge, pore water sensors and water content sensors are connected to the data collection system. The video camera, water pump and data collection system are turned on simultaneously to start the experiment (Fig. 8).

\section{Experiment procedure}

The particle composition under different fractal dimension and dry density can be back-calculated. According to the required slope angle $\left(35^{\circ}\right)$ and the slope size $(1.5 \mathrm{~m} \times 2.3 \mathrm{~m})$, the slope can be modified. To facilitate and ensure the homogeneity of the samples, the initial water content is set as $10 \%$, and the required water can be added and mixed uniformly with the gravelly soil. The soil can then be placed step by step on the modified slope. The thickness of the gravely soil is $35 \mathrm{~cm}$, and the soil samples were placed in three layers, with the thickness of the upper, middle and lower layer of 10, 10 and $15 \mathrm{~cm}$, respectively. After the lower layer is fully placed on the slope, the surface is scratched to avoid sliding slip plane between the lower and the mid-layer. Then the pore-water pressure sensors and water content sensors are placed in the correct locations. The sampling process is then repeated until the slope meets the requirements of the experiment. The rainfall gauge was placed on the edge of slope (as shown in Figs. 6 and $8 a$ ) with the aim of collecting real time precipitation data during the experiment. In order to analyze the formation mechanism, and to better illustrate the underlying reasons for each phenomenon in the experimental process, the video camera was placed in front of the slope. When the experiment was started, the artificial rainfall system, data collection system and video camera were turned on simultaneously. 


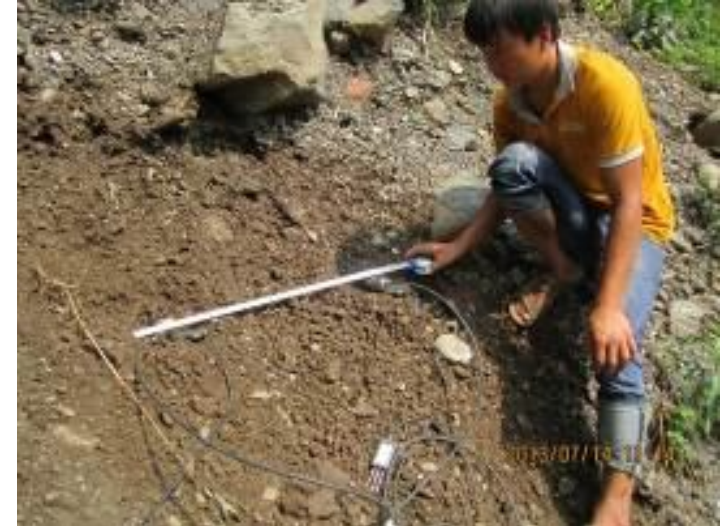

a. Buried sensors

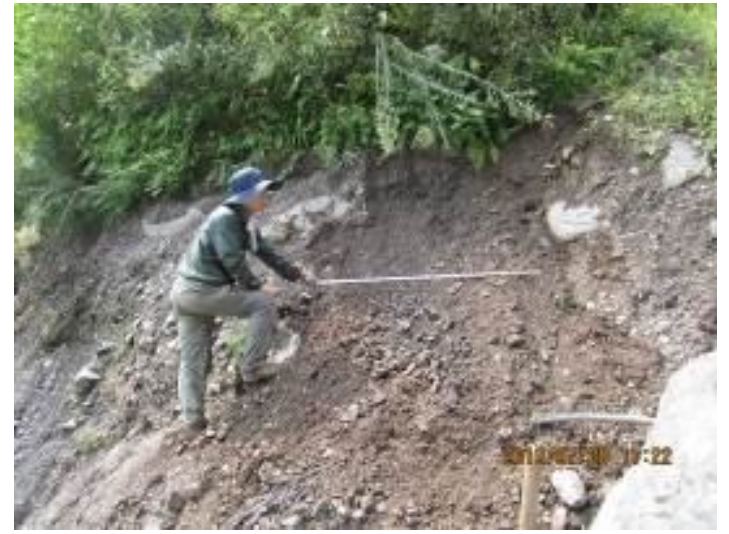

c. Measure the size of the slope

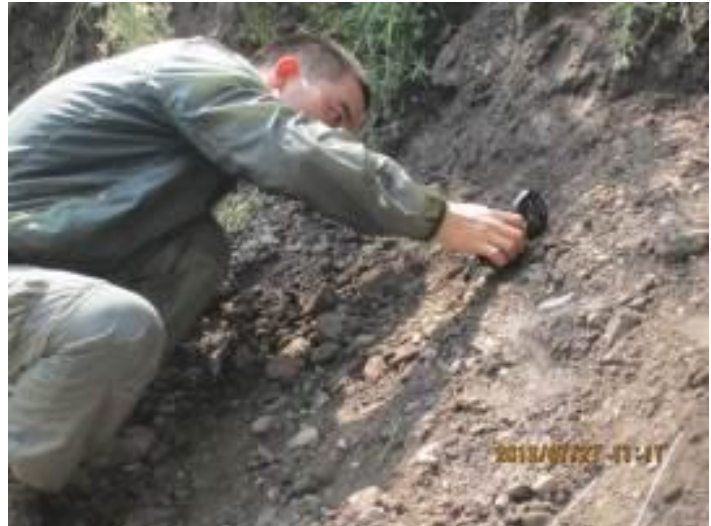

b. Control slope angle

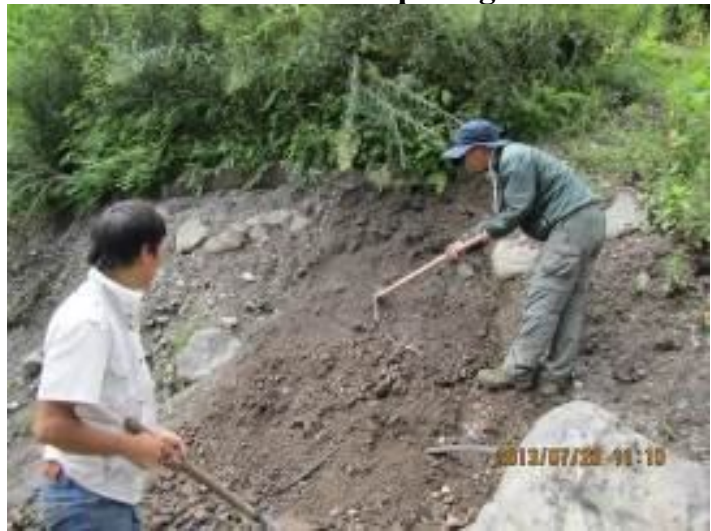

d. Bury sensors

Figure 7. Experiment preparation

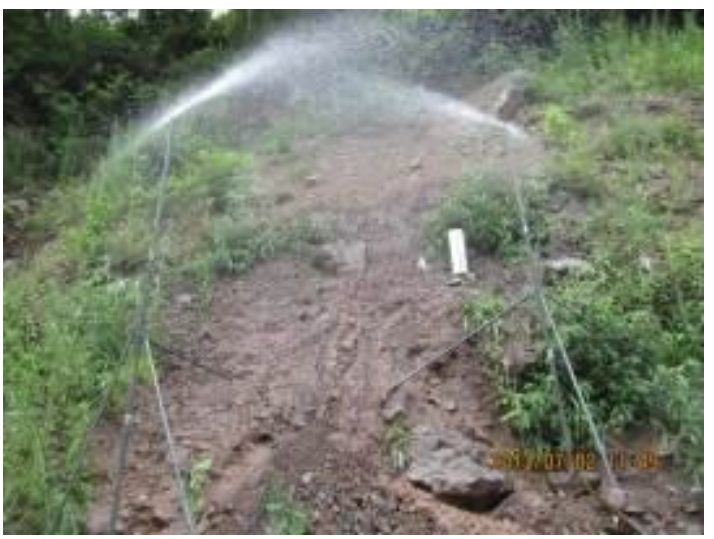

a. Rainfall process

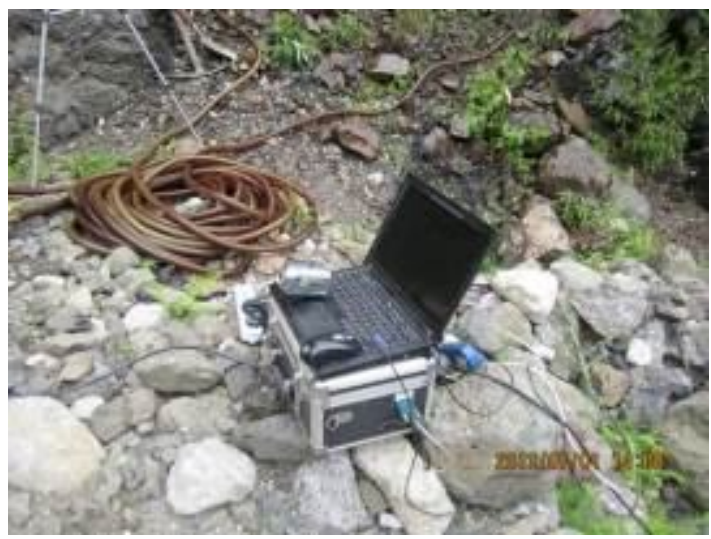

b. Data collection system

Figure 8. In-situ experiment progress

\section{Results}

Following careful analysis of the results of the in-situ artificial rainfall experiments, we found that for gravelly soil, certain conditions are critical for debris flow initiation, and the gravelly soil that mobilized into debris flows manifests obvious criticality: The results indicate that while the fractal dimension of the slope is less than 2.4, regardless of the density or cumulative rainfall amount, no debris flows occurred during the whole 
rainfall process. Moreover, as the fractal dimension of the soil increased, the probability of debris flow initiating on the slope becomes higher, the unit weight of the formed debris flow becomes larger, varying from dilute debris flow (unit weight less than $1.8 \mathrm{~g} / \mathrm{cm}^{3}$ ) to viscous debris flow (unit weight greater than $1.8 \mathrm{~g} / \mathrm{cm}^{3}$ ).

By comparing the data from all the experiments the following results can be established: under identical dry density, slope angle and rainfall condition, the gravelly soil with lower fractal dimension (less than 2.4) experienced short term creep deformation during the rainfall process, which thereafter tends to stabilize, and the slope maintains its stability during the subsequent rainfall process. Under such circumstances, no overland runoff was witnessed on the slope and the infiltrated water flowed out at the base of the slope mainly through internal flow. In addition, the internal flow entrained the vast majority of the fine particles. Therefore the soil structure can be changed dramatically, and obvious sinking can be witnessed on the slope (Fig. 9). Due to the washing away of fine particles, the pore water sensors and water content sensors were finally exposed (Fig. 9d). But no debris flow was witnessed from beginning to the end of the experiments.

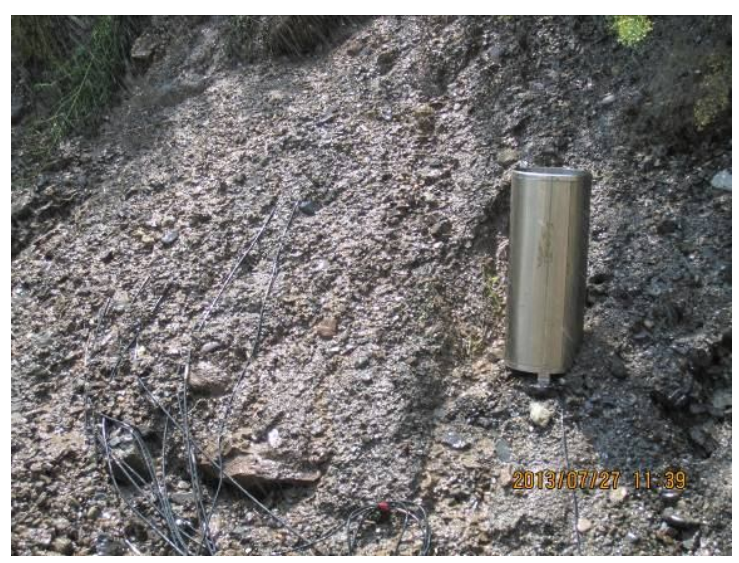

a. At the beginning of the experiment

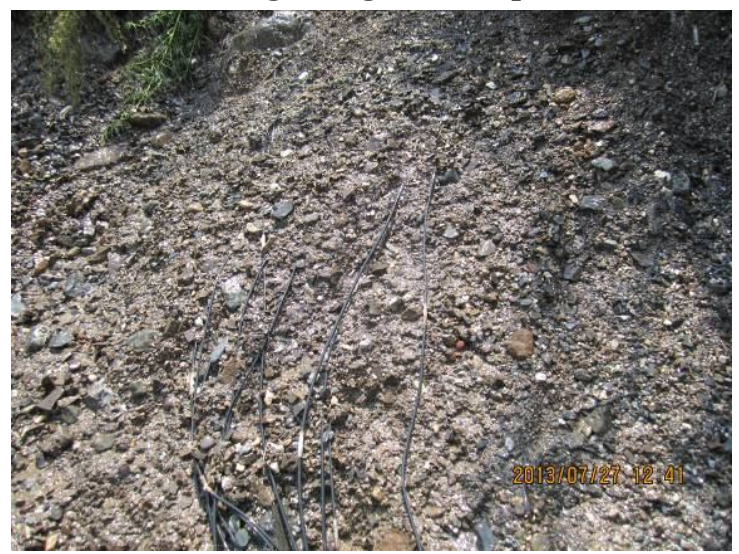

c. During the process of the experiment

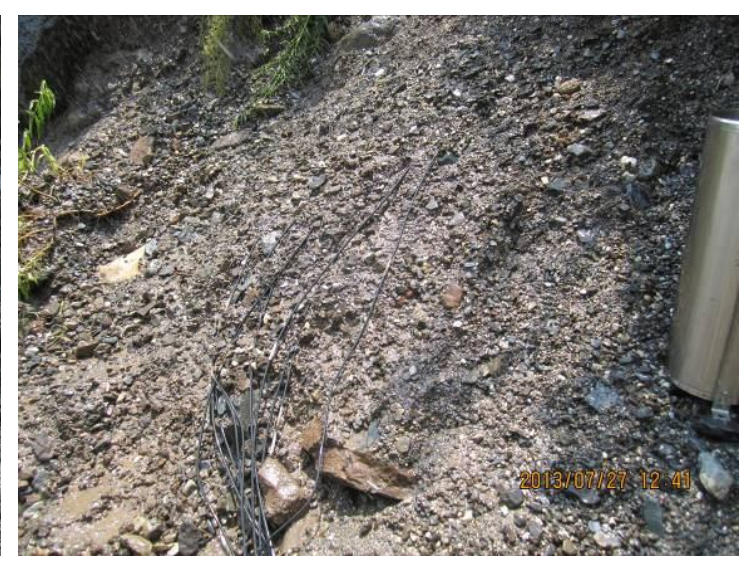

b. During the process of the experiment

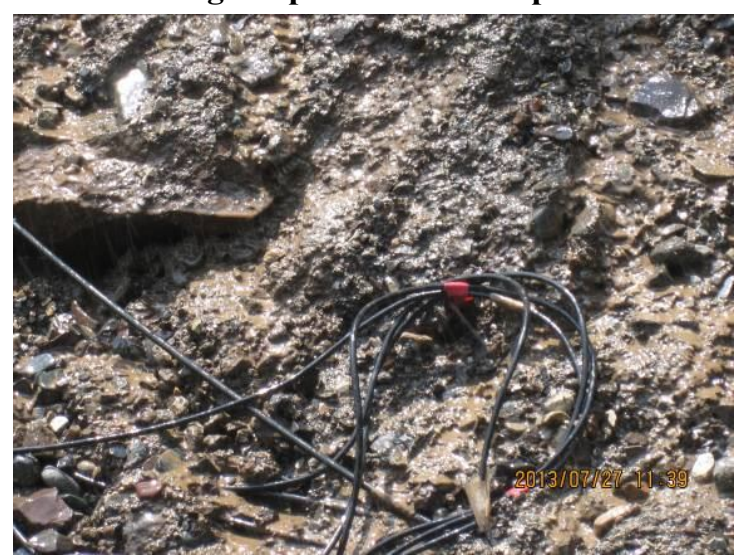

d. At the end of the experiment (the sensors were exposed due to the continuous rainfall)

Figure 9. Phenomenon of the experiment (here the fractal dimension of the soil sample is 2.35)

After the fractal dimension exceeds 2.4, the creep deformation lasted longer and the distance of the creep deformation is larger during the rainfall process. By analyzing the recorded videos, two types of runoff were identified: internal runoff and overland 
runoff. Comparing the internal runoff we found that for larger fractal dimension (larger than 2.4) very little of the fine particle fraction were washed out by the internal runoff. As the rainfall process continued, many erosion gullies were induced by overland flow, which subsequently caused an accumulation of material collapsed from banks. This subsequently failed as shallow slides when saturated, transforming the process into debris in a second stage. After this initial phase, the debris flow volume increased rapidly by a chain of subsequent cascading processes starting with collapses of the sidewalls, damming and breaching, leading to a rapid widening of the erosion channel. In terms of erosion amount, the subsequent mechanisms were much more important than the initial one. The damming and breaching were found to be the main reasons for the huge magnitude of the debris flows, and this agrees well with previous research $(\mathrm{Hu}$ et al., 2016).

The samples from the formed debris flows were collected and analyzed. Comparing them, we found that the unit weight of the debris flow increases as the fractal dimension increase. For slopes with fractal dimension 2.4, the unit weight of the formed debris flow is around $1.63 \mathrm{~g} / \mathrm{cm}^{3}$, but the unit weight of samples taken from slope with fractal dimension 2.7 is more than $1.82 \mathrm{~g} / \mathrm{cm}^{3}$. These results indicate that as the fractal dimension of the soil increases, the formed debris flow is likely to change from dilute to viscous debris flow. These results demonstrate that the unit weight of the formed debris flow is closely linked to particle size distribution. This can provide useful information for future debris flow prevention. For slope with identical fractal dimension, as the dry density increases, debris flow initiation process takes a longer time, but for slopes with fractal dimension smaller than 2.4, no debris flows were witnessed.

Analyzing the pore-water pressure and water content pressure we found that regardless of whether a debris flow was formed or not, the pore water pressure and water content curves exhibit similar characteristics. At the beginning of the rainfall process, the pore water pressure gradually increased to its peak value and then decreased to a given value, as shown in Figure 10. But the water content first increased and then maintains a peak value for the duration of the rainfall. For soil with different fractal dimension and dry density, the peak value and fixed value may show some variations, but the trends are identical. Here we take the pore water pressure and water content from the slope with fractal dimension 2.35 as an example to illustrate this phenomenon (Fig. 10).

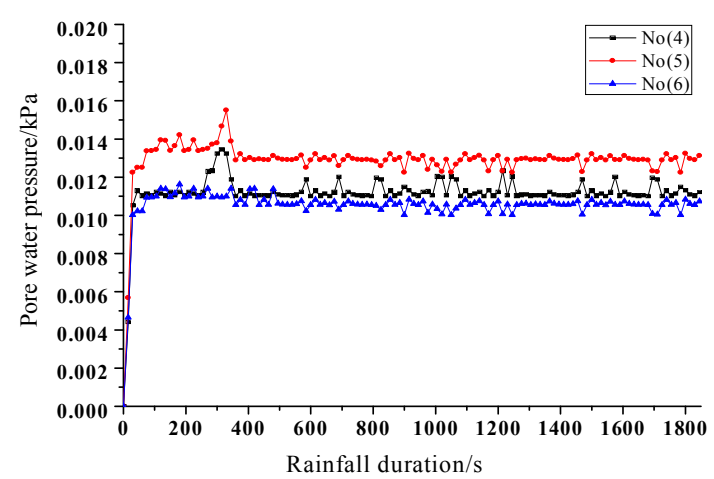

a. pore-water pressure curves

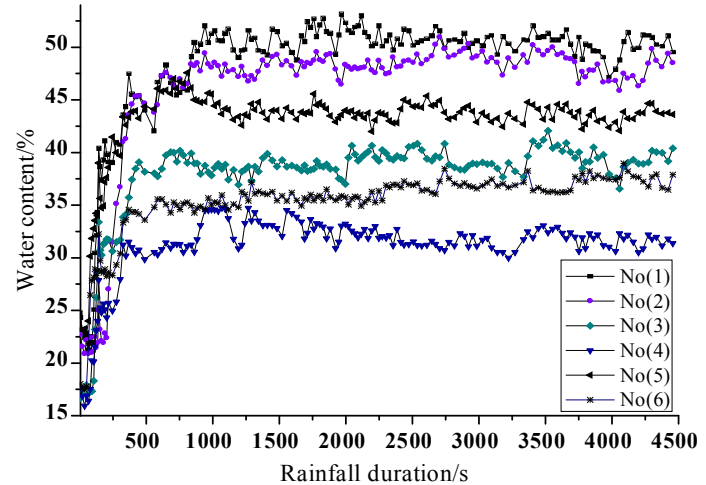

b. water content curves

Figure 10. Pore-water pressure curves and water content curves of gravelly soil with fractal dimension 2.3 
Analyzing the pore water pressure curves and debris flow initiation process, it was also found that debris flow initiation always happens before the occurrence of peak pore water pressure. For slopes with different fractal dimensions, the time from initiation to the peak value of pore water pressure varied greatly.

\section{Discussion}

Based on the analysis in section 2.2, we concluded that the fine particle portion increases with the increasing of fractal dimension. Previous research (He et al., 2014) revealed that permeability coefficient and fractal dimension displays an exponential relationship, and the function is presented in Equation 8, where k denotes coefficient of permeability, $\mathrm{D}$ is fractal dimension of the gravelly soil, and $\rho_{d}$ is dry density. Through Equation 8 we found that for a given dry density, the permeability coefficient decreased dramatically as fractal dimension increased. The in-situ artificial rainfall experiment agrees well with previous research: for slope with lower fractal dimension (less than 2.4), no overland flow was identified during the entire experiment, and no obvious peak pore-water pressure was witnessed, and the fluctuation of the pore water pressure is relatively small, as shown in Figure 11 . This is mainly due to the high permeability, so water can freely infiltrate and flow out of the slope in a short time without causing a sharp increase in pore water pressure. Surface sinking of the slope was induced mainly due to the losses of fine particles and structural reorganization. Moreover, the strength of the slope decreased slightly due to a small pore-water pressure increase. Therefore, the strength is sufficient to resist the sliding forces, and the slope can maintain its stability.

$$
k=f\left(\rho_{d}, D\right)=6.051 \times 10^{4} \times \rho_{d}^{-7.297} \times D^{-9.196}
$$

As the fractal dimension increases, the fine particle fraction increases gradually, and the permeability of the soil decreases rapidly. During the rainfall process, the infiltrated water cannot release timely. This will cause a sharp increase in pore water pressure. Effective stress and pore water pressure is negatively correlated, a sharp increase in pore water pressure directly causing a dramatic decrease in effective stress. Under the combined effect of pore-water pressure increasing, along with an increased entrained and scour capacity of the overland flow, the large-scale debris flow was finally formed. For slopes with fractal dimension more than 2.4, during the rainfall process debris flow was identified. But comparing the videos and pore water pressure curves, we found that even though all such slopes formed debris flows, the mechanism of debris flow formation were radically different.

For slopes with fractal dimension ranging from 2.4 to 2.6, the formation mechanism can be understood using Soil Mechanics: the coefficient of permeability of the slope is larger than slopes with fractal dimension more than 2.6 (He et al., 2014). Therefore, under same rainfall conditions, more water infiltrated into the slope, which resulted in a raised pore-water pressure. Due to the continuous rainfall, the pore-water pressure increased a lot, and finally reached its peak value. The soil strength decreased to its minimal value, and the debris flow formed thereby. Theoretically, debris flow should be formed simultaneously with pore-water pressure reaching its peak value. Owing to the sensitivity of the sensors, it takes a period of time for the sensors to record the data, so 
the collected data lags behind the real situation. This is the reason why initiation of debris flow appeared to be ahead of the occurrence of peak pore water pressure. For slopes with fractal dimension more than 2.6 , the infiltration capacity is relatively lower, little rainfall can infiltrate into the slope. Debris flow formed under such condition can be shown to be due to a run-off generated mechanism (Hu et al., 2016, 2014; Kean et al., 2013b; Yu et al., 2014). Superficial run-off erosion first generated a small erosion gully in the upper part of the slope and the eroded material was deposited in the lower part. The debris flow process initiated through saturation and breaching of this deposited material, which blocked the run-off water. Bed erosion and lateral erosion then continued to enlarge the erosion gully providing future material to the debris flow at lower concentrations. The subsequent erosion peaks with high debris-flow solid concentrations, were related to the cyclic damming by side-wall failures and dam breaching which enlarged the erosion gully, the size and the unit weight of the debris flow (Coe et al., 2008b; Kean et al., 2013a).

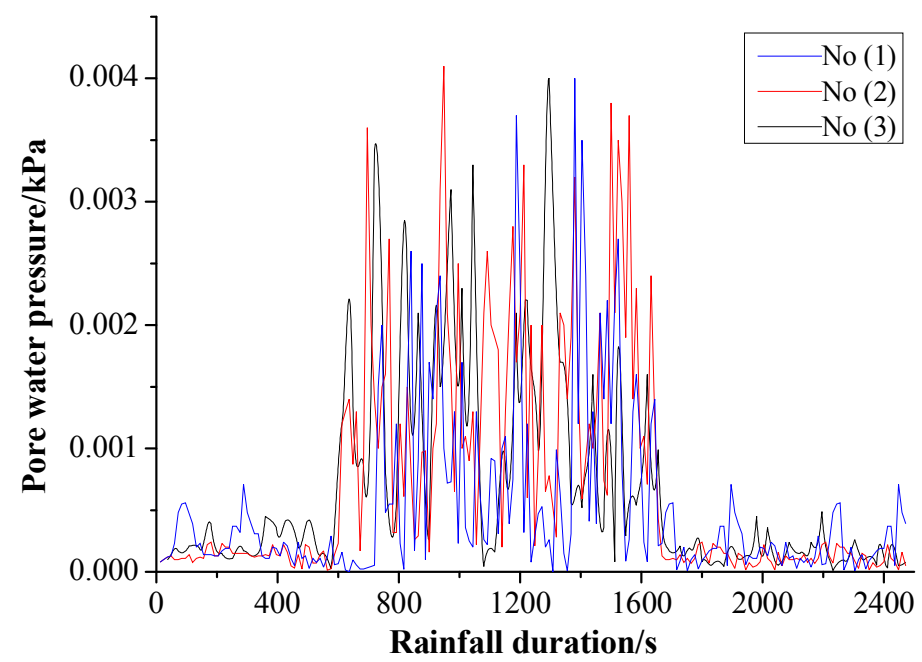

Figure 11. Pore water pressure curves (slope with fractal dimension 2.35)

The criticality is mainly due to the internal structure of the gravelly soil, which significantly influenced its coefficient of permeability and strength. When the fractal dimension is less than 2.4, the soil is constituted of coarse particles, and the strength is mainly determined by occlusal forces. Therefore, the permeability is larger and the strength is relatively higher, so the infiltrated water can be released freely without causing a pore-water pressure increase, and the slope can maintain its stability very well under continuous rainfall conditions. When the fractal dimension ranges from 2.4 to 2.6, cohesion forces and the internal friction angle both determined the soil strength, and the permeability coefficient allows water infiltrate into the slope and causes a pore-water pressure increase. The permeability coefficient is smaller than the rainfall intensity, so the rainfall will generate two types of water flow: internal flow and overland flow. The internal flow results in decreasing of soil strength, and the overland flow provides impact force to trigger debris flow. That is why slopes with fractal dimension ranges from 2.4 to 2.6 are more susceptible to debris flow. As the fractal dimension increases to more than 2.6, the soil structure properties are mainly governed by the fine particles. The soil strength is determined by the internal friction angle. Previous research found 
that water content has a slight influence on internal friction angle. Hence, soil strength decreased slightly during the whole rainfall duration. For soils with fractal dimension larger than 2.6, the coefficient of permeability is extremely small, and the precipitation mainly resulted in overland water flow. Under these circumstances, debris flow initiation is triggered by overland flow, and the mechanism can be understood using hydraulic theory.

\section{Conclusions}

From sampling and sieve testing the particle size distributions of the gravelly soil in debris flow source area can be established. With the aid of fractal theory, the fractal dimension of the samples can be computed and the fractal characteristics can be determined. Using the fractal characteristics of the gravelly soil, an in-situ artificial rainfall experiments were conducted, and some important findings were made. Following an analysis of the aforementioned experimental results, the following conclusions can be drawn:

(a) Gravelly soil in debris flow source area is mainly concentrated in one fractal dimension. The dimension value ranges from about 2.25 to 2.98. A close link between fractal dimension and particle size distribution was revealed: as fractal dimension increased, the particle composition tends to be more evenly.

(b) Our previous research established that the strength and permeability coefficient of gravelly soil is governed by fractal dimension (particle size composition or distribution). As fractal dimension increased, the permeability coefficient decreased (He et al., 2014).

(c) Gravelly soil manifests criticality, which means that slopes with fractal dimension less than 2.4 cannot (or can only with extremely low probability) mobilise into debris flow, regardless of rainfall intensity, duration or cumulative rainfall. Moreover, as the fractal dimension of the soil increases, the probability of the slope mobilising into debris flow becomes higher, and the unit weight of the formed debris flow becomes larger, ranging from dilute debris flow (unit weight less than $1.8 \mathrm{~g} / \mathrm{cm}^{3}$ ) to viscous debris flow (unit weight greater than $1.8 \mathrm{~g} / \mathrm{cm}^{3}$ ).

(d) As the fractal dimension falls into different intervals, the appropriate debris flow formation or initiation mechanism can be understood using different theories: For slopes with fractal dimension ranges from 2.4 to 2.6 and more than 2.6, the formation mechanism can be understood using soil mechanics and hydraulics theories, respectively.

(e) Debris flow initiation and peak pore-water pressure did not occur simultaneously. The initiation time always happened before the occurrence of peak pore-water pressure.

The results presents in this article provide a useful tool for debris flow forecast and prevention in the future. With the aim of improving the accuracy of debris flow prediction, the soil composition characteristics can be analyzed, and the fractal dimension of the soils can be computed. Comparing the fractal dimension with the results in this paper, a preliminary evaluation of the probability of debris flow initiation can be made. Furthermore, a comprehensive analysis of the slope angles, meteorological conditions and watershed features in the study area should be completed, then the scale, property and probable dynamic processes and dynamic characteristics of the potential debris flow can then be assessed. This can greatly 
improve the accuracy of prediction, and provide important information for disaster mitigation.

Acknowledgements. This work was financially supported by National Key R\&D Program of China (No. 2018YFC1505205), the National Natural Science Foundation of China (41302284 \&41661144028), and the doctoral fund of Henan Polytechnic University (Grant No B2015-58), and Henan Postdoctoral Foundation (Grant No.19030069).

\section{REFERENCES}

[1] Bacchini, M., Zannoni, A. (2003): Relations between rainfall and triggering of debrisflow: case study of Cancia (Dolomites, Northeastern Italy). - Natural Hazards and Earth System Science 3(1-2): 71-79.

[2] Bathurst, J. C., Burton, A., Ward, T. J. (1997): Debris flow run-out and landslide sediment delivery model tests. - Journal of Hydraulic Engineering 123(5): 410-419.

[3] Berti, M., Simoni, A. (2005): Experimental evidences and numerical modelling of debris flow initiated by channel runoff. - Landslides 2(3): 171-182.

[4] Brayshaw, D. H. M. A. (2009): Debris flow initiation and sediment recharge in gullies. Geomorphology 109(3-4): 122-131.

[5] Cannon, S. H., Gartner, J. E., Rupert, M. G., Michael, J. A., Rea, A. H., Parrett, C. (2010): Predicting the probability and volume of postwildfire debris flows in the intermountain western United States. - Geological Society of America Bulletin 122(1-2): 127-144

[6] Carpinteri, A., Lacidogna, G., Pugno, N. (2004): Scaling of energy dissipation in crushing and fragmentation: a fractal and statistical analysis based on particle size distribution. International Journal of Fracture 129(2): 131-139.

[7] Chen, H., Lee, C. F. (2000): Numerical simulation of debris flows. - Canadian Geotechnical Journal 37(1): 146-160.

[8] Chen N. C., Wang, X., Di, B. (2004): Testing study on strength reduction of gravelly soil in triggering areaof debris flow under earthquake. - Chinese Journal of Rock Mechanics and Engineering 23(16): 2743-2747 (in Chinese).

[9] Chen, N. S., Zhou, W., Yang, C. L., Hu, G. S., Gao, Y. C., Han, D. (2010): The processes and mechanism of failure and debris flow initiation for gravel soil with different clay content. - Geomorphology 121(3-4): 222-230.

[10] Chen, Y. (1998): Fractal Geometry. - Earthquake Press, Beijing.

[11] Coe, J. A., Cannon, S. H., Santi, P. M. (2008a): Introduction to the special issue on debris flows initiated by runoff, erosion, and sediment entrainment in western North America. Geomorphology 96(3): 247-249.

[12] Coe, J. A., Kinner, D. A., Godt, J. W. (2008b): Initiation conditions for debris flows generated by runoff at Chalk Cliffs, central Colorado. - Geomorphology 96(3): 270-297.

[13] Coussot, P., Meunier, M. (1996): Recognition, classification and mechanical description of debris flows. - Earth-Science Reviews 40(3): 209-227.

[14] Giannecchini, R., Naldini, D., Avanzi, G. D. A., Puccinelli, A. (2007): Modelling of the initiation of rainfall-induced debris flows in the Cardoso basin (Apuan Alps, Italy). Quaternary International 171: 108-117.

[15] Giannecchini, R., Galanti, Y., D’Amato Avanzi, G., Barsanti, M. (2016): Probabilistic rainfall thresholds for triggering debris flows in a human-modified landscape. Geomorphology 257: 94-107.

[16] Gregoretti, C., Degetto, M., Boreggio, M. (2016): GIS-based cell model for simulating debris flow runout on a fan. - Journal of Hydrology 534: 326-340. 
[17] He, N., Chen, N. S., Zhu, Y. H., Yang, J. Y., Yang, C. L. (2014): Experiment study of fractal feature and relationship between fractal dimension and permeability coefficient of gravelly soil in debris flow source area. - Yantu Lixue/Rock and Soil Mechanics 35(9): 2543-2548.

[18] He, S., Liu, W., Li, X. (2016): Prediction of impact force of debris flows based on distribution and size of particles. - Environmental Earth Sciences 75(4): 1-8.

[19] Ho, K., Leroi, E., Roberds, B. (2000): Quantitative Risk Assessment: Application, Myths and Future Direction. - International Society for Rock Mechanics, Lisbon.

[20] Hogan, D. L., Schwab, J. W. (1991): Stream channel response to landslides in the Queen Charlotte Islands, BC: changes affecting pink and chum salmon habitat. - Proceedings of the $15^{\text {th }}$ Northeast Pacific Pink and Chum Salmon Workshop, Parksville, BC, pp. 222236.

[21] Hu, W., Xu, Q., Rui, C., Huang, R. Q., Asch, T. W. J., Zhu, X., Xu, Q. Q. (2014): An instrumented flume to investigate the initiation mechanism of the post-earthquake huge debris flow in the southwest of China. - Bulletin of Engineering Geology and the Environment 74(2): 393-404.

[22] Hu, W., Dong, X. J., Xu, Q., Wang, G. H., van Asch, T. W. J., Hicher, P. Y. (2016): Initiation processes for run-off generated debris flows in the Wenchuan earthquake area of China. - Geomorphology 253: 468-477.

[23] Hungr, O., McDougall, S., Wise, M., Cullen, M. (2008): Magnitude-frequency relationships of debris flows and debris avalanches in relation to slope relief. Geomorphology 96(3): 355-365.

[24] Hwang, S. I., Powers, S. E. (2003): Using particle-size distribution models to estimate soil hydraulic properties. - Soil Science Society of America Journal 67(4): 1103-1112.

[25] Iverson, R. M., LaHusen, R. G. (1989): Dynamic pore-pressure fluctuations in rapidly shearing granular materials. - Science 246(4931): 796-799.

[26] Iverson, R. M., Reid, M. E., LaHusen, R. G. (1997): DEBRIS-FLOW MOBILIZATION FROM LANDSLIDES 1. - Annual Review of Earth and Planetary Sciences 25(1): 85138.

[27] Jakob, M. (2005): A size classification for debris flows. - Engineering Geology 79(3): 151-161.

[28] Johnson, A. C., Swanston, D. N., McGee, K. E. (2000): Landslide initiation, runout, and deposition within clearcuts and old-growth forests of Alaska. - JAWRA Journal of the American Water Resources Association 36(1): 17-30.

[29] Kean, J. W., McCoy, S. W., Tucker, G. E., Staley, D. M., Coe, J. A. (2013): Runoffgenerated debris flows: Observations and modeling of surge initiation, magnitude, and frequency. - Journal of Geophysical Research: Earth Surface 118(4): 2190-2207.

[30] Li, Y., Liu, J., Chen, X., Wei, F. (2007): Grain composition and erosive equilibrium of debris flows. - Journal of Mountain Science 4(1): 71-76.

[31] Liu, C.-N., Dong, J.-J., Peng, Y.-F., Huang, H.-F. (2009): Effects of strong ground motion on the susceptibility of gully type debris flows. - Engineering Geology 104(3): 241-253.

[32] Lu, Y. (2013): Study for the effect mode and mechanism of Earthquakes \& droughts on debris flows. - Doctorate. University of Chinese Academy of Sciences, Huairou, China.

[33] MacDonald, A., Maurice, L., Dobbs, M., Reeves, H., Auton, C. (2012): Relating in situ hydraulic conductivity, particle size and relative density of superficial deposits in a heterogeneous catchment. - Journal of Hydrology 434: 130-141.

[34] Maggioni, V., Nikolopoulos, E. I., Marra, F., Destro, E., Borga, M. (2016): Satelliterainfall estimation for identification of rainfall thresholds used for landslide/debris flow prediction. - Proceedings EGU General Assembly Conference Abstracts 18: 15006.

[35] Miller, D. J., Burnett, K. M. (2008): A probabilistic model of debris-flow delivery to stream channels, demonstrated for the coast range of Oregon, USA. - Geomorphology 94(1): 184-205. 
[36] Ningsheng, C., Peng, C., Xiaoying, W., Baofeng, D. (2004): Testing study on strength reduction of gravelly soil in triggering area of debris flow under earthquake. - Chinese Journal of Rock Mechanics and Engineering, 23(16): 2743-2747 (Chinese paper).

[37] Papa, M., Medina, V., Ciervo, F., Bateman, A. (2013): Derivation of critical rainfall thresholds for shallow landslides as a tool for debris flow early warning systems. Hydrology and Earth System Sciences 17(10): 4095-4107.

[38] Park, D. W., Lee, S. R., Vasu, N. N., Kang, S. H., Park, J. Y. (2016): Coupled model for simulation of landslides and debris flows at local scale. - Natural Hazards 1-30.

[39] Saito, H., Nakayama, D., Matsuyama, H. (2010): Relationship between the initiation of a shallow landslide and rainfall intensity_duration thresholds in Japan. - Geomorphology 118(1): 167-175.

[40] Shimizu, H., Murata, S., Ishida, T. (2011): The distinct element analysis for hydraulic fracturing in hard rock considering fluid viscosity and particle size distribution. International Journal of Rock Mechanics and Mining Sciences 48(5): 712-727.

[41] Smadja, J. (1992): Studies of climatic and human impacts and their relationship on a mountain slope above Salme in the Himalayan Middle Mountains, Nepal. - Mountain Research and Development 12(1): 1-28.

[42] Turkington, T., Remaître, A., Ettema, J., Hussin, H., Westen, C. (2016): Assessing debris flow activity in a changing climate. - Climatic Change 137(1): 1-13.

[43] Varnes, D. J. (1978): Slope Movement Types and Processes. - Transportation Research Board Special Report, Washington, DC.

[44] Wang, G., Sassa, K. (2003): Pore-pressure generation and movement of rainfall-induced landslides: effects of grain size and fine-particle content. - Engineering Geology 69(1): 109-125.

[45] Wang, Y., Zhao, B., Li, J. (2017): Mechanism of the catastrophic June 2017 landslide at Xinmo Village, Songping River, Sichuan Province, China. - Landslides 4: 1-13.

[46] Yang, D., Herath, S., Musiake, K. (2002): A hillslope-based hydrological model using catchment area and width functions. - Hydrological Sciences Journal 47(1): 49-65.

[47] Yang, Z.-Y., Pourghasemi, H. R., Lee, Y.-H. (2016): Fractal analysis of rainfall-induced landslide and debris flow spread distribution in the Chenyulan Creek Basin, Taiwan. Journal of Earth Science 27(1): 151-159.

[48] Yong, L., Xiaoqing, C., Kaiheng, H., Shufen, H. (2005): Fractality of grain composition of debris flows. - Journal of Geographical Sciences 15(3): 353-359.

[49] Yong, L., Xiaojun, Z., Pengcheng, S., Yingde, K., Jingjing, L. (2013): A scaling distribution for grain composition of debris flow. - Geomorphology 192: 30-42.

[50] Yu, B., Zhu, Y., Wang, T., Chen, Y., Zhu, Y., Tie, Y., Lu, K. (2014): A prediction model for debris flows triggered by a runoff-induced mechanism. - Natural Hazards 74(2): 1141-1161.

[51] Zhang, S. J., Wei, F. Q., Liu, D., Yang, H. J., Jiang, Y. H. (2014a): A regional-scale method of forecasting debris flow events based on water-soil coupling mechanism. Journal of Mountain Science 11(6): 1531-1542.

[52] Zhang, S., Yang, H., Wei, F., Jiang, Y., Liu, D. (2014b): A model of debris flow forecast based on the water-soil coupling mechanism. - Journal of Earth Science 25(4): 757-763.

[53] Zhou, X., Cui, P., Li, Z. (2012): Development and application of integrated test equipment for permeability and settlement of gravelly soil in triggering area of debris flow. - Chinese Journal of Rock Mechanics and Engineering 31(6): 1281-1289. 